\title{
A cost-effectiveness analysis of alternative survey methods used for the monitoring of marine recreational fishing in France
}

\author{
Bellanger Manuel ${ }^{1,{ }^{*}}$, Levrel Harold ${ }^{1,2}$ \\ ${ }^{1}$ Ifremer, IUEM, UMR 6308 AMURE, Rue Dumont d'Urville, F-29280, Plouzane, France \\ 2 UMR CIRED, AgroParisTech, Campus du Jardin Tropical, 45 bis, Avenue de la Belle Gabrielle, 94736 \\ Nogent-sur-Marne Cedex, France \\ *Corresponding author : Manuel Bellanger, email address : manuel.bellanger@ifremer.fr \\ harold.levrel@agroparistech.fr
}

\begin{abstract}
:
The growth of marine recreational activities raises the issues of the current lack of knowledge on these activities and the information required to assess their potential impacts. Indeed, the monitoring of unrecorded activities is a great challenge, especially when basic information, such as the size of the population practicing the different activities, is unknown. In this paper, the experience of the monitoring of marine recreational fishing was used to carry out a diagnosis study to assess the cost-effectiveness of survey methods used in France between 2004 and 2012. Costs of alternative surveys were balanced with data quality, and particular attention was paid to potential biases. Results showed that the involvement of citizens through diary surveys could be a cost-effective option when the recruitment of participants complied with randomness and representativeness requirements. The outcomes of this study provide useful insights to help managers and decision makers implement monitoring schemes in similar contexts.
\end{abstract}

\section{Highlights}

- Precise costs of the different types of survey are provided and compared. Accuracy of effort and catch rate estimates is poor for most surveys. Diary surveys with involvement of citizens were found particularly cost-effective. Recruitment of participants must ensure randomness and representativeness. Findings are relevant for future monitoring schemes in a variety of contexts.

Keywords : Marine recreational fishing, Monitoring, Cost-effectiveness analysis, Fisheries management 


\section{Introduction}

The growth of marine recreational activities can be a source of ecological, economic and sociological opportunities and problems (Arlinghaus and Cooke 2009). Intensive recreational activities are known to be a threat to biodiversity, at least at a local scale (Addessi 1994; Milazzo et al. 2002; Kerbiriou et al. 2008, 2009). Also, the increase of recreational activities may have positive socio-economic impacts since it is generating new sources of income (Gormsen 1997; Badalamenti et al. 2000; Davenport and Davenport 2006). Finally, recreational activities have a core social role for coastal populations. In order to be able to understand and address these issues at different scales, it has been highlighted that the development of an efficient monitoring system is a key element (Green et al. 2005). Until recently, it was still not acknowledged by policy-makers that the monitoring of recreational activities can have a major importance in the management of the uses of biodiversity (Arlinghaus 2006). Although there are recent examples of marine planning and management programs taking monitoring effort into consideration (Dalton et al. 2010), this has not led to public investment in long term recreational activities monitoring schemes, except maybe for the monitoring of recreational fishing in the USA and in Australia (ICES 2010; Smallwood et al. 2010; Jones and Pollock 2013). Overall, resources allocated to study the impacts of recreational activities are generally much lower in comparison with commercial activities. Marine recreational activities cover:

- snorkelling

- scuba diving 
- sailing/boating

- $\quad$ marine surf sports

- $\quad$ seaside/bathing activities

- recreational fishing (including spearfishing and netting).

These activities are difficult to monitor due to the heterogeneity of the practices and their seasonality, the diversity of their locations and the "nomadism" of the users (Smallwood et al. 2011). In addition, even if there are examples of mandatory registration programs (Gaudin and De Young 2007), licensing or registration are not required for most of the recreational activities (ICES 2010). All these elements lead to an almost systematic lack of knowledge regarding basic information such as the size of the population practicing the different types of recreational activities. Hence the question of how to develop the most reliable monitoring system to the lower cost for society is certainly of great interest.

It is important to assess the efficiency of previous pilot studies to help the decision makers choose among the different schemes of recreational activities monitoring. Because there are a wide variety of monitoring methods that are difficult to compare, it is challenging to carry out some diagnosis regarding what are the most cost-effective recreational activities monitoring systems. One way to overcome issue is to focus on one specific institutional context. To illustrate the type of diagnosis it is possible to do, the authors of this paper attempt to balance costs and effectiveness of alternative surveys that have been developed in France to monitor recreational fishing at the national scale between 2004 and 2012 . The paper is structured through three simple questions: 
(i) What are the costs of the different types of survey developed in France between 2004 and 2012? (ii) What is the quality of the collected information? (iii) Which types of surveys are the most cost-effective?

The paper concludes with recommendations on which types of surveys are suitable for the monitoring of recreational fishing, considering their feasibility in the French context. This discussion will attempt to highlight what are the key elements of marine recreational activities monitoring schemes to be considered by managers who want to develop such information systems.

\section{Materials and methods}

The International Council for the Exploration of the Sea (ICES, 2010) states that recreational fishery surveys can be divided into two categories: one for screening the population of recreational fishers and characterize their social profiles, and one for assessing the catch rates and the fishing effort. Screening surveys are off-site and include telephone, postal mail and online surveys. Their goal is to characterize the population of recreational fishers in size, fishing avidity, practiced activities and socio-economic composition. In the absence of a complete registry of recreational fishers - which can be obtained through a compulsory licence system (Gaudin and De Young 2007; Hartill et al. 2012) -, screening surveys are a key element as they can provide a basis for extrapolating catches. However, catch-effort surveys can give precise information on number, weight, size, kept/discards and specificity of catches in relation with location, type of gear and seasonality. Onsite surveys and diary surveys are the two main types of catch-effort surveys 
(ICES 2010). Combining catch-effort surveys with screening surveys allows extrapolation of catches to a national scale. Although complementary data on habits, location of activities, gear types and expenditures are valuable information, this paper focuses on the quality of catch and effort data.

France has carried out both screening surveys and catch-effort surveys on recreational fishing between 2004 and 2012 (Table 1). The surveys have all been designed and conducted by Ifremer, the official institute in charge of the monitoring of recreational fishing in France with regard to the French Ministry in charge of the Fisheries management and the Data Collection Framework European Directive (EC 2001, 2010) and its monitoring requirements. The data collection was subcontracted to a polling institute (BVA). The fact that both the institute which has conducted the surveys and the polling institute which has collected data have been the same for the last 9 years helped provide a standardized cost-effectiveness analysis since the nature of the contracts, the price rates and the statistical methods used during these years can be considered as homogeneous. The analysis focused on the survey methods presented in Table 1 but it is worth noting that there exist other types of surveys such as mail and online surveys. Therefore the types of surveys considered in the analysis represent only a subset of all types of surveys that can be done.

The first national scale screening survey that was conducted by Ifremer was an omnibus Random Dialled Digit (RDD) national telephone survey in 2004. An omnibus survey is a compilation of several surveys on different topics within the same interview. The polling institute used a pre-constituted representative sample 


\begin{tabular}{|c|c|c|c|c|}
\hline Year & Type of survey & Study Area & $\begin{array}{l}\text { Number of } \\
\text { surveys }^{\mathrm{a}}\end{array}$ & $\begin{array}{c}\text { Number of } \\
\text { interviewed fishers }\end{array}$ \\
\hline 2004 & Omnibus Telephone survey & $\begin{array}{l}\text { National territory, including overseas } \\
\text { islands }\end{array}$ & 14054 & 301 \\
\hline 2006 & Telephone survey & Metropolitan national territory & 15085 & 1016 \\
\hline 2007 & On-site survey & $\begin{array}{l}\text { Atlantic coast, English Channel and } \\
\text { Mediterranean Sea }\end{array}$ & 1775 & 1775 \\
\hline 2009 & Telephone survey & $\begin{array}{l}\text { Coastal region of the North Sea, } \\
\text { English Channel and Bay of Biscay }\end{array}$ & 15090 & 467 \\
\hline 2010 & $\begin{array}{l}\text { Random Dialled Digit Recruitment } \\
\text { (RDDR) Diary survey }\end{array}$ & $\begin{array}{l}\text { Coastal region of the North Sea, } \\
\text { English Channel and Bay of Biscay }\end{array}$ & 1170 & 190 \\
\hline 2011 & Telephone survey & $\begin{array}{c}\text { Region of the North Sea, English } \\
\text { Channel, Bay of Biscay and } \\
\text { Mediterranean Sea }\end{array}$ & 16130 & 792 \\
\hline 2012 & $\begin{array}{l}\text { Random Dialled Digit Recruitment } \\
\text { (RDDR) Diary survey }\end{array}$ & $\begin{array}{c}\text { Region of the North Sea, English } \\
\text { Channel, Bay of Biscay and } \\
\text { Mediterranean Sea }\end{array}$ & 846 & 175 \\
\hline 2012 & $\begin{array}{l}\text { Random Dialled Digit Recruitment } \\
\text { (RDDR) Telephone-Diary survey }\end{array}$ & $\begin{array}{c}\text { Region of the North Sea, English } \\
\text { Channel, Bay of Biscay and } \\
\text { Mediterranean Sea }\end{array}$ & 519 & 60 \\
\hline 2012 & $\begin{array}{l}\text { Volunteers recruited through an } \\
\text { Association of Recreational Fishers } \\
\text { (VARF) Diary survey }\end{array}$ & $\begin{array}{l}\text { Region of the North Sea, English } \\
\text { Channel, Bay of Biscay and } \\
\text { Mediterranean Sea }\end{array}$ & 1471 & 149 \\
\hline
\end{tabular}

Table 1: History of recreational fishing surveys carried out in France

${ }^{a}$ For the telephone surveys, the number of surveys corresponds to the number of households interviewed but considering all the non-response the total number of exploited phone numbers is actually much greater. For example, in 2006 there were 172000 exploited phone numbers for the realisation of 15085 surveys. 
of the French population formed of people who agreed to be contacted for such surveys. It is therefore cheaper than a "standard" telephone survey (the sampling and screening costs are shared). The side effect of an omnibus survey is that the questionnaire has to remain short and the questions cannot be contextualized. A telephone survey allows a longer questionnaire and oversampling coastal areas in order to get more interviews with recreational fishers, which is impossible in an omnibus survey. For these reasons, Ifremer chose to conduct telephone surveys for the following screening surveys in 2006, 2009 and 2011 (in the rest of this paper we denote by "telephone survey" a RDD telephone survey which is not part of an omnibus survey.). The telephone surveys consisted of two phases: first, a 3 minutes interview to obtain socio-demographic details about the household members and the number of recreational fishers per household; afterwards, a 12 minutes interview designed specifically for recreational fishers, if any in the household.

Ifremer conducted an on-site survey in 2007 for which recreational fishers were intercepted at fishing access sites (Herfaut et al. 2013). Two diary surveys for which participants were recruited during the previous RDD telephone surveys were conducted in 2009 (Rocklin et al. 2014) and 2012. These surveys are referred to as the Random Dialled Digit Recruitment (RDDR) diary surveys in the rest of the article. Recreational fishers participating in RDDR diary surveys self-reported fishing trip and catch details during a whole year on provided diaries which were returned quarterly. For the RDDR diary survey conducted in 2012, the diarists were asked whether they wanted to be part of a telephone-diary survey consisting in a weekly telephone appointment with an interviewer where the diarists reports 
details about his fishing trips since last appointment. The goal of this extensive survey was to identify some potential non response bias related to zero-bag trips. 60 fishers agreed to participate in this "extensive" diary survey while the others continued the self-reporting survey. In addition, a diary survey where volunteers were recruited through a collaborating association of recreational fishers (Promopêche) was experimented in 2012. This last survey is referred to as the VARF diary survey (VARF stands for Volunteers from an Association of Recreational Fishers). The VARF diary survey was conducted in the same way as the RDDR diary survey, only the method for the recruitment of participants was different. The idea was to assess if it was possible to reduce strongly the costs of the survey through the use of the recreational fisher networks and to identify some potential bias associated to this sample.

\subsection{Costs of surveys}

A precise history of quotes and contracts corresponding to the surveys conducted between 2004 and 2012 (Table 1) was available. The total costs that were invested for the implementation of each survey could then be computed. A standardisation of costs was required to account for inflation over the period 2004-2012. All costs are presented in "equivalent 2012" euros (adjusted for inflation as of 2012) so that an equitable comparison between the costs of surveys given for different years could be made.

The units of comparison which have been used are the total costs per recreational fisher (the total costs of a survey divided by the number of fishers for which 
information has been collected at least once) and the total costs per fishing trip (the total costs of a survey divided by the number of fishing trips). The costs per recreational fisher are an intuitive unit to balance the differences in terms of investments required between the different types of survey and appraise their feasibility on a large sample. It can be used as a proxy for the comparison of the costs of screening surveys. On the other hand, the costs by fishing trip are also an interesting unit enabling to get comprehensive costs for each trip for which information including catches details has been reported. Trip level data informs on the variability of catch rates at the trip level, and the number of sampled fishing trips influences the precision of a global catch extrapolation. The cost per trip is therefore a useful proxy for the comparison of the costs of catch-effort surveys in complement to the cost per fisher.

\subsection{Quality of information}

One of the key elements allowing the assessment of the reliability of recreational fishing studies is the estimation of catches. During telephone surveys, interviewees were asked to recall details of their catches (number, total weight, mean length per species) for the last fishing trip, but fish weight and length of each catch were not asked because such accuracy is irrelevant for recall surveys. In addition interviewees were asked to estimate the catches in number per species over the last 12 months but this information cannot be considered precise enough and was mainly used to characterise the intensity of the fishers' activity. During on-site surveys, catch data was collected by the interviewers. However, some 
respondents found too intrusive that the interviewer measured precisely their catches, which caused some refusals. In some cases, it was chosen to lower the inconvenience and to realise an eye-estimation of weight/length rather than a precise measurement of catches, but this cannot be considered as a reliable estimation. On the other hand, diary surveys provided weight and length data of each catch. Indeed, diarists were supplied with measurement equipments and a guidebook for species identification, and they were briefed on how to collect such data.

\section{$\underline{\text { Risks of biases: }}$}

A recreational fishing survey program should aim at minimizing bias and maximizing precision of estimators of important parameters (National Research Council 2006; Jones and Pollock 2013). Each type of survey has its risks of bias which should be subject to a close evaluation in order to consolidate the estimations. The different types of bias identified in the recreational fisheries survey literature include:

- recall bias;

- representativeness bias/sampling error;

- non response bias;

- declaration bias/response error.

The main issues related to these biases are succinctly summarised in the Table 2. 


\begin{tabular}{|c|c|c|c|c|c|}
\hline Type of bias & Definition & $\begin{array}{c}\text { Types of survey } \\
\text { affected }\end{array}$ & Issues & $\begin{array}{l}\text { Addressing the } \\
\text { issues }\end{array}$ & References \\
\hline Recall bias & $\begin{array}{c}\text { Bias due to long recall } \\
\text { period }\end{array}$ & Telephone & $\begin{array}{l}\text { - Recall period of } 2 \text { or more months } \\
\text { are known to result in significant over- } \\
\text { estimates of effort and catch } \\
\text { - Aggregated data catch }\end{array}$ & $\begin{array}{l}\text { - Using } \\
\text { complementary } \\
\text { surveys for catch- } \\
\text { effort evaluation }\end{array}$ & Pollock et al. 1994 \\
\hline $\begin{array}{l}\text { Representativeness } \\
\text { bias / Sampling error }\end{array}$ & $\begin{array}{l}\text { Difference between an } \\
\text { estimation obtained by } \\
\text { surveying a sample and the } \\
\text { value that would have been } \\
\text { obtained if all individuals } \\
\text { had been surveyed }\end{array}$ & $\begin{array}{l}\text { On-site } \\
\text { Telephone-Diary } \\
\text { Diary }\end{array}$ & $\begin{array}{l}\text { - Difficulties of accessing night and } \\
\text { private fishing } \\
\text { - Inability to cover all fishing access } \\
\text { points and all strata of the sampling } \\
\text { frame } \\
\text { - Low participation of occasional } \\
\text { fishers } \\
\text { - Self-selection of participants }\end{array}$ & $\begin{array}{l}\text { - Using remotely } \\
\text { operated cameras } \\
\text { - Using prior } \\
\text { information (even } \\
\text { anecdotal) to inform } \\
\text { the survey design }\end{array}$ & $\begin{array}{l}\text { National Research } \\
\text { Council } 2006 \\
\text { Smallwood et al. } \\
2012\end{array}$ \\
\hline Non response bias & $\begin{array}{l}\text { Occurs when some sampled } \\
\text { individuals do not respond } \\
\text { and the answers of } \\
\text { respondents are not } \\
\text { representative of the } \\
\text { originally selected sample }\end{array}$ & All types & $\begin{array}{l}\text { - Refusals } \\
\text { - Omission of zero bag trips }\end{array}$ & $\begin{array}{l}\text { - Improving the } \\
\text { response rate }\end{array}$ & Fisher 1996 \\
\hline $\begin{array}{l}\text { Declaration bias / } \\
\text { Response error }\end{array}$ & $\begin{array}{l}\text { Occurs when participants } \\
\text { respond idiosyncratically } \\
\text { according to their } \\
\text { convenience }\end{array}$ & $\begin{array}{l}\text { Telephone } \\
\text { Diary } \\
\text { Telephone-Diary }\end{array}$ & $\begin{array}{l}\text { - Exaggeration of catches (prestige } \\
\text { bias) } \\
\text { - Declaration to be in accordance with } \\
\text { legal rules (bag limit, minimum size) } \\
\text { - Digit preference }\end{array}$ & $\begin{array}{l}\text { - Confronting results } \\
\text { with catch-rates } \\
\text { observed on-site }\end{array}$ & Pollock et al. 1994 \\
\hline
\end{tabular}

Table 2: Description of biases in recreational fisheries surveys 


\section{Inspection of biases and precision:}

The quality of information can be characterized by the accuracy of the data and the precision of estimators. Accuracy is associated with the magnitude of biases while precision is associated with statistical random error. Usually, increasing the sample size increases the precision but does not improve the accuracy. The mean and the standard deviation for the annual number of trips per fisher, the number of catches per trip and the weight per catch were calculated for every survey mentioned in the Table 1. The mean estimates provided elements to appraise the accuracy of the collected information and to expose evidences or indications on the potential existence of biases in the different studies. The standard deviation estimates gave information on the precision of estimators. As the 2004 omnibus survey, the 2009 telephone survey and the 2010 RDDR diary survey were focusing on the Sea Bass recreational fisheries, the Sea Bass is the only species for which we were able to provide indicators across all studies.

\section{Extrapolation of catches:}

The extrapolation of catches $C$ was obtained through the formula:

$$
C=E \times C P U E
$$

where $E$ is the effort (i.e. the number of fishing trips) and $C P U E$ are the catches per unit of effort (i.e. the catches per trip). The standard deviation of extrapolation estimates was computed with the following formula which is commonly found in the statistical literature (Goodman 1960):

$$
\sigma_{\bar{E} \times \overline{C P U E}}=\sqrt{\left(\bar{E} \sigma_{\overline{C P U E}}\right)^{2}+\left(\overline{C P U E} \sigma_{\bar{E}}\right)^{2}}
$$


where $E$ and $C P U E$ are considered as independent random variables, $\bar{E}$ is the mean of $E$, and $\sigma_{\bar{E}}$ is the standard deviation of $\bar{E}$. Spearman's non parametric test can be used to assess whether the assumption of independence is acceptable (Spearman 1904).

\subsection{Cost-effectiveness}

Formally, the cost-effectiveness $C E$ can be considered as a function of 4 parameters

$$
C E=f(x, y, z, c)
$$

where $x$ is the magnitude of the biases, $y$ is the level of questionnaire length constraints, $Z$ is the level of difficulty to cover the whole target population, $c$ is the cost, and

$$
\begin{aligned}
& \frac{\partial f}{\partial x}<0 \\
& \frac{\partial f}{\partial y}<0 \\
& \frac{\partial f}{\partial z}<0 \\
& \frac{\partial f}{\partial c}<0 .
\end{aligned}
$$

(2.3.2), (2.3.3), (2.3.4) and (2.3.5) respectively express that an increase of biases, an increase of questionnaire length constraints, more difficulties to cover the whole target population or an increase of the costs leads to a loss of cost-effectiveness. Parameters $x$ and $c$ have been explained in the previous sections. The level of 
questionnaire length constraints (parameter $y$ ) relates to the amount of time available and the maximum number of questions that may be asked before a significant proportion of respondents do not complete the questionnaire. It can be assessed with the feedback from the test phase of the questionnaire and with the dropout rates. The difficulty to cover the whole target population (parameter $z$ ) conveys the inability of finding enough participants for all strata of the sampling frame. This can be evaluated by observing the differences between the expected and the achieved sampling frames and with the sharing from experience of pollsters.

Practically, an explicit formula for $t$ cannot be provided and the materials required to quantify precisely the loss of cost-effectiveness that would be associated to an increase of one of these four variables were not available. However, relative comparisons between all types of survey for each variable can give clues to appraise the relative cost-effectiveness of the different types of survey.

The cost-effectiveness analysis of recreational fisheries surveys that France has experimented between 2004 and 2012 was twofold. The first part of this analysis used expert judgement to compare the different types of survey according to each of the four parameters $x, y, z$ and $c$ taken independently. It was based on a qualitative scoring methodology similar to the effectiveness assessment approaches developed in Cifuentes et al. (2000), Courrau (1999) and Ervin (2003). Each parameter was attributed a score in $\{1,2,3,4,5\}$ where 1 corresponds to a very good score (e.g. $x=1$ means the biases are very small or controllable) and 5 corresponds to a very bad score (e.g. $x=5$ means the magnitude of biases is very 
high). A score of 5 in one of the parameters implies that the overall quality/feasibility of the survey is critically affected. Therefore, to maximize the cost-effectiveness, a survey needs to minimize its maximum score. This method did not intend to directly compute a score for the overall cost-effectiveness since the relative importance of each parameter as well as their interactions were not quantified. Instead the scores should be considered as inter-survey comparisons of cost-effectiveness key elements. The scoring was established by an expert group directed by Ifremer including economists, fisheries scientists and statisticians (Bellanger et al. 2013). Scores were based on qualitative and quantitative results regarding the costs of the surveys and the quality of information as well as sharing from experience of pollsters.

The second part of the analysis investigated the sensitivity of cost-effectiveness to bias magnitude based on a methodological development that is exposed hereinafter.

We assumed a cost-effectiveness proxy indicator, focused on bias magnitude and costs, of the form:

$$
C E(x, c)=c^{-\alpha} \times x^{-\beta}
$$

with $\alpha \geq 0$ and $\beta \geq 0$ the relative weights given to the costs and the bias magnitude. Varying the values of $\alpha$ and $\beta$ then allows to evaluate the sensitivity of cost-effectiveness to bias magnitude. The greater $\beta$ is as compared to $\alpha$, the more the bias magnitude $x$ influences $C E$. For example, if $\beta=0, C E$ only depends on the costs $c$. The proxy for the parameter $c$ can be the costs by fisher or the costs by trip as defined in Section 2.1. For the bias magnitude $x$, there is large empirical 
evidence in the recreational fisheries survey literature indicating that the biases listed in Table 2 result in an overestimation, at least in average, of effort and catch. As such, the minimum estimates across all survey types can be considered the closest to the real values of mean effort and mean catch per unit of effort. Let $E_{i}$ and $C P U E_{i}$ be the mean estimates of effort and catch per unit of effort for the survey type $i$. The proxy used for $x$ was:

$$
x=\frac{E_{i}}{E_{\min }}+\frac{C P U E_{i}}{C P U E_{\min }}
$$

where $E_{\min }$ (resp. $\left.C P U E_{\min }\right)$ is the minimum across all survey types of the mean estimate of $E$ (resp. $C P U E$ ). The parameter $x$ in eq. 2.3.7 can be seen as a proxy of the ratio between the estimated catch extrapolation and the real value of total catch, hence the magnitude of biases.

Using the results established for the costs of the surveys and the quality of information, the sensitivity of cost-effectiveness to bias magnitude could be estimated for the different types of survey. Since values of $C E$ are only useful for the relative comparisons (absolute values of $C E$ are somewhat unimportant), the weight given to the costs in eq. 2.3.6 was fixed to $\alpha=1$ and $C E$ was estimated for different values of $\beta$ the weight given to bias magnitude.

\section{Results}

\subsection{Costs of surveys}

The Table 3 exposes the costs (adjusted for inflation as of 2012) for all the types of survey that have been experimented between 2004 and 2012. For the types of 
survey that have been used multiple times (e.g. telephone survey), the total costs have been averaged. The total costs include the costs of data collection and the costs of data recording, validation and the first univariate statistical treatments. For the on-site survey and the telephone surveys, it is the global budget allocated to the poll institute that has conducted the interviews and the data recording. For the diary surveys, it includes the money spent on recruiting diarists, measurement equipment supplied to diarists, postal fees and the budget allocated to the organization responsible for gathering diaries, recording and validating the data.

\section{$\underline{\text { Screening surveys: }}$}

The total costs of the omnibus survey were $41,240 €$. Only 301 out of 14,054 interviewees declared being recreational fishers and then answered the protracted interview about recreational fishing activities. Therefore the average cost by interviewed fisher was $137 €$. On the other hand, the total costs of the telephone survey were $101,380 €$, and the average cost by fisher was $134 €$. This indicates that the reduction of sampling and screening costs in omnibus surveys was compensated by oversampling coastal areas in telephone surveys, so that the costs by fisher of the omnibus and the telephone surveys were in fact equivalent.

The Table 1 allows calculating the number of short ( 3 mins) and long ( $3+12$ mins) interviews conducted during the 2006, 2009 and 2011 telephone surveys. In average, this results in:

- Number of interviews: 15,435

- Number of short (3mins) interviews: 14,677

- Number of long $(3+12$ mins $)$ interviews: 758 . 


\begin{tabular}{|l|c|c|c|c|c|c|}
\cline { 2 - 7 } & \multicolumn{2}{c|}{ Screening surveys } & \multicolumn{4}{c|}{ Catch-effort surveys } \\
\cline { 2 - 7 } & $\begin{array}{c}\text { Omnibus } \\
\text { Telephone survey } \\
2004\end{array}$ & $\begin{array}{c}\text { Telephone survey } \\
2006,2009 \& 2011\end{array}$ & $\begin{array}{c}\text { On-site survey } \\
2007\end{array}$ & $\begin{array}{c}\text { Random Dialled } \\
\text { Digit Recruitment } \\
\text { (RDDR) Diary } \\
\text { survey } \\
2010 \& 2012\end{array}$ & $\begin{array}{c}\text { Random Dialled Digit } \\
\text { Recruitment (RDDR) } \\
\text { Telephone-Diary } \\
\text { survey } \\
2012\end{array}$ & $\begin{array}{c}\text { Volunteers recruited } \\
\text { through an } \\
\text { Association of } \\
\text { Recreational Fishers } \\
\text { (VARF) Diary survey } \\
2012\end{array}$ \\
\hline Total costs $(€)$ & 41,240 & 101,380 & 184,300 & 25,825 & 29,625 & 14,150 \\
\hline Number of fishers & 301 & 758 & 1775 & 183 & 60 & 149 \\
\hline $\begin{array}{l}\text { Number of fishing } \\
\text { trips reported }\end{array}$ & - & - & 1775 & 1008 & 519 & 1471 \\
\hline $\begin{array}{l}\text { Costs by fisher } \\
(€ / \text { fisher) }\end{array}$ & 137 & 134 & 104 & 141 & & 494 \\
\hline Costs by trip $(€ /$ trip) & - & - & 104 & 26 & & 57 \\
\hline
\end{tabular}

Table 3: costs of studies (in "equivalent 2012" $€$, i.e. adjusted for inflation as of 2012) 
This shows that the number of short interviews (i.e. interviews with non-fisher respondents) represented more than $95 \%$ of the total number of interviews (only $3.8 \%$ of French households have at least one recreational fisher), which explains why the cost by fisher of telephone surveys was high.

\section{Catch-effort surveys:}

The average cost of each on-site interview performed during the 2007 study was $104 €$. In comparison, the average cost by fisher of the RDDR diary survey was higher $(141 €)$. However, in the RDDR diary survey the information collected for each fisher related not only to one trip but to all fishing trips within a year. Therefore, when considering the costs by trip, the RDDR diary survey was cheaper than the onsite survey (26€vs 104€).

As one can expect, the cost per trip for the RDDR telephone-diary survey was higher than for the RDDR diary survey (57€vs $26 €)$. Also, the RDDR telephonediary survey had very high average costs by fisher (494€), almost five times more than on-site interviews (104€). However it is interesting to note that the cost by trip of the RDDR telephone-diary survey (57€) was lower than on-site survey (-45\%). The average cost by fisher for the VARF diary survey was equal to $95 €$, which was slightly lower than on-site survey $(-9 \%)$ and about 33\% cheaper than the cost by fisher for the RDDR diary survey. When the total costs were calculated for each reported fishing trip, the VARF diary survey appeared to be the cheapest (10€vs $104 €$ for on-site survey and $26 €$ for the RDDR diary survey). 


\subsection{Quality of information}

The Sea Bass (Dicentrarchus labrax) is the most targeted and emblematic species of the French recreational fisheries. Effort and catch rate were calculated for the Sea Bass fisheries for each survey type (Table 4). For the types of survey that have been used multiple times (the telephone survey and the RDDR diary survey), the indicators have been averaged (and weighted by the sample sizes).

\section{$\underline{\text { Recall bias: }}$}

Effort estimation obtained from screening surveys data (respectively 25.7 and 23.7 trips per year for omnibus and telephone surveys) was about twice higher than from RDDR diary survey data (12.0 trips per year). Combining recall and representativeness biases, the estimate from on-site survey was the highest (42.4 trips per fisher and per year).

It is also interesting to compare catch rate indicators such as the average number and the total weight of bass caught per trip. The average catch rate estimates for the RDDR diary surveys were the lowest of all types of survey ( 0.88 bass/trip and 0.78 $\mathrm{kg} /$ trip). Screening surveys exhibited high catch rates which can be partly linked to recall bias.

\section{Representativeness bias/sampling error:}

The fishers participating in the RDDR telephone-diary and the VARF diary surveys were more avid than the average recreational fishers population (because occasional fishers do not see the point of an intensive reporting and the fishers involved in recreational fishers associations are usually very regular fishers). This 


\begin{tabular}{|c|c|c|c|c|c|c|}
\hline & \multicolumn{2}{|c|}{ Screening surveys } & \multicolumn{4}{|c|}{ Catch-effort surveys } \\
\hline & $\begin{array}{c}\text { Omnibus } \\
\text { Telephone } \\
\text { survey } \\
2004\end{array}$ & $\begin{array}{l}\text { Telephone } \\
\text { survey } \\
2006,2009 \& \\
2011\end{array}$ & $\begin{array}{c}\text { On-site survey } \\
2007\end{array}$ & $\begin{array}{c}\text { Random Dialled } \\
\text { Digit Recruitment } \\
\text { (RDDR) Diary } \\
\text { survey } \\
2010 \& 2012\end{array}$ & $\begin{array}{c}\text { Random Dialled Digit } \\
\text { Recruitment (RDDR) } \\
\text { Telephone-Diary } \\
\text { survey } \\
2012\end{array}$ & $\begin{array}{c}\text { Volunteers recruited } \\
\text { through an Association } \\
\text { of Recreational Fishers } \\
\text { (VARF) Diary survey } \\
2012\end{array}$ \\
\hline $\begin{array}{l}\text { Annual number of } \\
\text { trips per bass fisher }\end{array}$ & 25.7 (29.1) & $23.7(37.7)$ & 42.4 (48.3) & $12.0(15.8)$ & 21.9 (23.3) & 21.4 (27.9) \\
\hline $\begin{array}{l}\text { Number of bass } \\
\text { caught per trip } \\
\text { (unit/trip) }\end{array}$ & $3.66(6.10)$ & $1.52(4.39)$ & $1.58(3.63)$ & $0.88(1.78)$ & $2.34(3.96)$ & 1.67 (3.92) \\
\hline $\begin{array}{l}\text { Weight of bass per } \\
\text { trip (kg/trip) }\end{array}$ & $4.15(8.54)$ & - & 1.28 (3.39) & $0.78(1.76)$ & $3.04(7.84)$ & $1.63(4.85)$ \\
\hline $\begin{array}{l}\text { Weight per bass } \\
\text { (kg/unit) }\end{array}$ & $1.33(1.10)$ & - & $0.81(0.63)$ & $0.89(0.81)$ & $1.30(1.21)$ & $0.97(0.84)$ \\
\hline $\begin{array}{l}\text { Annual number of } \\
\text { bass caught per } \\
\text { bass fisher (unit/year) }\end{array}$ & $94.1(189.5)$ & $36.0(118.8)$ & $67.0(171.8)$ & $10.6(25.5)$ & $51.2(102.4)$ & 35.7 (95.9) \\
\hline $\begin{array}{l}\text { Annual weight of } \\
\text { bass caught per } \\
\text { bass fisher (kg/year) }\end{array}$ & $106.7(250.5)$ & - & $54.3(156.5)$ & $9.4(24.5)$ & $66.6(185.7)$ & $34.9(113.3)$ \\
\hline
\end{tabular}

Table 4: effort and catch rate indicators including both released and kept fishes - mean (standard deviation) 
representativeness bias led to annual number of trips per fisher estimates (21.9 trips per year in the RDDR telephone-diary survey and 21.4 in the VARF diary survey) higher than the estimate for RDDR diary survey (12.0 trips). Similarly, very avid fishers are the ones who are more likely to be found on site, and the annual number of trips per fisher from on-site survey (42.4 trips) was clearly affected by representativeness bias.

More avid fishers are likely to have more experience and better catch rates, which means that an over-representation of avid fishers in the sample may lead to overestimate the catch rates. This is probably one of the reasons why the on-site survey, the RDDR telephone-diary and the VARF diary surveys showed greater average catch rates (respectively 1.58, 2.34 and 1.67 bass per trip) than the RDDR diary survey.

\section{Non-response bias:}

The comparison between the RDDR diary survey and the RDDR telephone-diary survey conducted in 2012 showed that the rate of zero bags in the RDDR diary survey was higher than in the RDDR telephone-diary survey where interviewers prompted the respondent to declare zero bag trips. Therefore, this specific type of non-response bias was controlled in RDDR diary surveys.

\section{Declaration bias/response error:}

The average weight per bass can reveal some prestige bias in off-site survey techniques. The lowest figure was observed for on-site survey (where prestige bias is avoided). RDDR and VARF diary surveys gave an average weight less than $1 \mathrm{~kg}$ 
per bass. The figure for the VARF diary survey was slightly higher than for the RDDR diary survey, which can be explained because the proportion of diarists fishing from a boat was more important. On the other hand, the average weight per bass in the omnibus survey $(1.33 \mathrm{~kg} /$ bass $)$ and the RDDR telephone-diary survey $(1.30 \mathrm{~kg} / \mathrm{bass})$ were dubiously high, which could be partially attributed to prestige bias. These differences between the survey techniques where the fisher is self-reporting the characteristics of his catches and the survey techniques which involve a telephone interview suggest that the telephone interaction between interviewer and interviewee may be one of the sources of prestige bias.

\section{Precision:}

The standard deviations associated with the effort and catch rate indicators were high compared to the means (Table 4). This exhibits the wide range and the skewness of the data, and it supports the fact that the behaviour and the success are various among recreational fishers. It also implies that the precision of estimates is a concern and that all results should be analysed with much care. It is worth noting that the standard deviation of the weight per bass was smaller than the mean for all survey types. That is because this biological parameter is intrinsically less subject to variability than effort and catch rate indicators.

\section{Extrapolation of catches:}

To illustrate the great variability of effort and catch rate estimations across the different types of survey, the Table 4 also presents a "rough" extrapolation of the average annual catches that simply consists in multiplying the average number of 
trips by the average number or weight of bass catches per trip. The Spearman test of correlation between the annual number of trips and the number of bass caught per trip indicated that the null hypothesis of these two variables being uncorrelated cannot be rejected $(p$-value $=0.49)$, which means that the standard deviation of extrapolation estimates could be computed too. The average annual number of basses caught per fisher varied from 10.6 to 67.0 basses for catcheffort surveys, and from 36.0 to 94.1 basses for screening surveys. The intersurvey type variability was even greater when looking at the average annual weight of bass caught per fisher. This highlights the poor accuracy of most surveys and the necessity of taking many precautions when using the results. It is indeed very difficult to be sure that the results of a survey can stand alone without confronting them to another source of data. Hence it is essential to combine at least two different types of survey for the monitoring of recreational fishing.

\subsection{Cost-effectiveness}

\subsubsection{Qualitative scoring}

Scoring indicators for the parameters which were identified to be crucial to evaluate the cost-effectiveness of the surveys are presented in Table 5. The reader should bear in mind that there is no attempt to quantify the relative importance of each parameter in terms of cost-effectiveness and that comparisons are to be made by row.

The omnibus and the telephone surveys had strong recall and declaration biases, hence they were not suitable for catch-effort assessments. However the random 


\begin{tabular}{|c|c|c|c|c|c|c|}
\hline & \multicolumn{2}{|c|}{ Screening surveys } & \multicolumn{4}{|c|}{ Catch-effort surveys } \\
\hline & $\begin{array}{l}\text { Omnibus } \\
\text { Telephone } \\
\text { survey } \\
2004\end{array}$ & $\begin{array}{c}\text { Telephone } \\
\text { survey } \\
2006,2009 \& \\
2011\end{array}$ & $\begin{array}{l}\text { On-site survey } \\
2007\end{array}$ & $\begin{array}{c}\text { Random Dialled } \\
\text { Digit Recruitment } \\
\text { (RDDR) Diary } \\
\text { survey } \\
2010 \& 2012\end{array}$ & \begin{tabular}{|c|} 
Random Dialled \\
Digit Recruitment \\
(RDDR) Telephone- \\
Diary survey \\
2012 \\
\end{tabular} & $\begin{array}{l}\text { Volunteers recruited } \\
\text { through an Association } \\
\text { of Recreational Fishers } \\
\text { (VARF) Diary survey } \\
2012\end{array}$ \\
\hline$x_{1}$ : Recall bias & 5 & 5 & 1 (catch) -5 (effort) & 2 & 1 & 2 \\
\hline $\begin{array}{l}x_{2}: \text { Representativeness } \\
\text { bias }\end{array}$ & 1 & 1 & 4 & 2 & 4 & 5 \\
\hline$x_{3}:$ Non response bias & 3 & 3 & 2 & 2 & 1 & 1 \\
\hline $\begin{array}{l}x_{4}: \text { Catch declaration } \\
\text { bias }\end{array}$ & 4 & 3 & 1 & 2 & 3 & 2 \\
\hline $\begin{array}{l}y: \text { Level of } \\
\text { questionnaire length } \\
\text { constraints }\end{array}$ & 5 & 2 & 1 & 2 & 3 & 2 \\
\hline $\begin{array}{l}\text { z: Difficulty to cover } \\
\text { the whole target } \\
\text { population }\end{array}$ & 1 & 1 & 4 & 2 & 3 & 3 \\
\hline$c:$ Costs & 3 & 3 & 3 & 1 & 5 & 1 \\
\hline
\end{tabular}

Table 5: qualitative cost-effectiveness indicators (1=low; 5=high) 
nature of their sampling schemes allowed obtaining a representative picture of the population of recreational fishers and its characteristics. Therefore they could be used as screening surveys. Because of length constraints, the questionnaire of the omnibus survey had to remain short and the information which was collected could not be detailed. Also, the questions could not be contextualized and response errors were higher. As the costs of the omnibus and the telephone surveys were equivalent, the cost-effectiveness of the telephone survey was considered higher.

The RDDR diary survey was found to be the most cost-effective catch-effort survey that was tested. Indeed, the evaluation of the cost-effectiveness parameters (Table 5) did not reveal any important quality/feasibility drawback for this type of survey as its maximum score was 2. This was not the case for the other catcheffort survey types since they all had at least one indicator with a score of 5 or 4 . On-site survey suffered from representativeness bias (because most of the fishers found on site were very avid fishers) and from recall bias (because effort estimation was based on recall). Also, on-site surveys were expensive and unsuitable to cover certain types of fishing. Consequently they were not considered as cost-effective as RDDR diary surveys.

The RDDR telephone-diary survey was primarily implemented to reinforce the quality of the data, especially to control non response bias associated with zerobag fishing trips. However, they were affected by catch declaration (prestige) bias. Also, because of the intensity of the reporting, the recruitment of participant was limited to avid fishers. Finally, RDDR telephone-diary surveys were very expensive. For these reasons it was judged that this type of survey was not cost- 
effective and that its use for the monitoring of recreational fishing at a national scale was not appropriate.

The use of the networks of recreational fishers for the recruitment of volunteer diarists has proven to reduce strongly the costs of diary surveys. However, the representativeness bias of the VARF diary survey was so important that the use of their data for catch extrapolation was inappropriate. Thus VARF diary surveys could not be considered cost-effective for the catch-effort assessment in recreational fisheries. In line with these results, the coupling of a telephone survey and a RDDR diary survey was found the most cost-effective scheme among the methods that France has tested for the monitoring of marine recreational fisheries.

\subsubsection{Sensitivity to the magnitude of biases}

Using the costs (Table 3) and the effort and catch rate estimates (Table 4) established for the different types of surveys, a cost-effectiveness proxy indicator $(C E)$ was computed following the methodology presented in Section 2.3. The variations of this indicator according to the weight given to bias magnitude (Fig. 1a-c) illustrate the trade-offs between costs and data quality. As expected from its analytical definition (see eq. 2.3.6), $C E$ is a decreasing function of the parameter $\beta$ that determines the sensitivity to the magnitude of biases.

For screening surveys (Fig. 1a), $C E$ was estimated using the cost by fisher as a proxy of $c$, the number of trips as a proxy of $E$, and the number of bass caught per trip as a proxy of $C P U E$. The values of $C E$ for the omnibus and the telephone surveys were similar for $\beta=0$, which was consistent with the fact the 
costs by fisher were equivalent for these two types of survey. When $\beta>0$, the cost-effectiveness of the telephone survey was found higher than for the omnibus survey. That is because the bias magnitude estimated from $E$ and $C P U E$ was more important for the omnibus survey.

For the catch-effort surveys, the product of the number of bass caught per trip times the weight per bass was used as a proxy of $C P U E$, and two cost proxies were alternatively used: the cost by fisher (Fig. 1b) and the cost by trip (Fig. 1c). In both cases, the cost-effectiveness of the RDDR diary survey appeared to be less affected by biases as $C E$ was found to be greater for the RDDR diary survey than for the other types of catch-effort survey when $\beta>1$ (Fig. 1b,c). This result is consistent with the qualitative assessment presented in Section 3.3.1. Being cheaper but more affected by biases than the RDDR diary survey, the VARF diary survey appeared to perform well only for small values of $\beta$. Notably, $C E$ was greater for the VARF diary survey than for the on-site survey regardless of the value of $\beta$. The RDDR telephone-diary survey was the least cost-effective when considering the cost by fisher (Fig. 1b) and the on-site survey performed poorly when considering the cost by trip (Fig. 1c). 


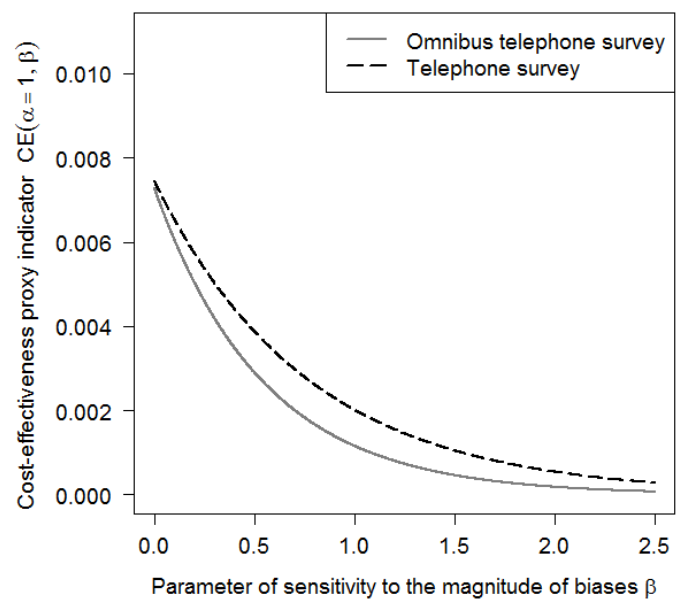

(a)

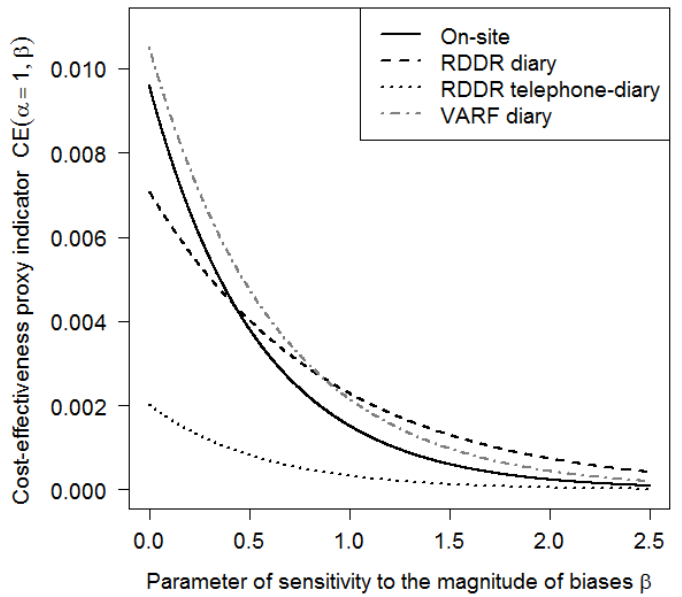

(b)

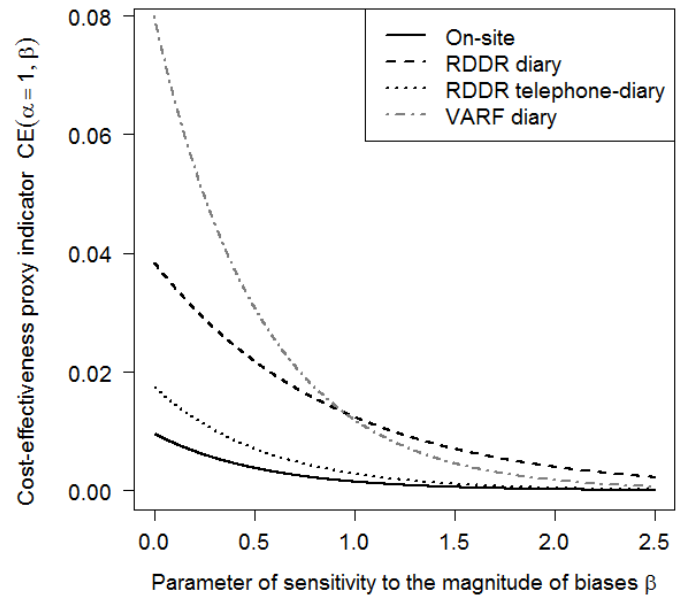

(c)

Figure 1: Sensitivity of cost-effectiveness to the magnitude of biases. (a) screening surveys, cost proxy=cost by fisher; (b) catch-effort survey, cost proxy=cost by fisher; (c) catch-effort survey, cost proxy=cost by trip. 


\section{Discussion}

\subsection{Concluding remarks}

The comparison between the different monitoring systems allowed to draw several practical conclusions. First, RDD telephone surveys can be used as screening surveys for the monitoring of unrecorded recreational activities. The strong advantage of this type of survey is the good coverage of the population regardless of the practices that usually vary among recreational users. Besides, despite growing concerns about the use of landline phonebooks as sampling frames because of the increasing preponderance of mobile-only households, a recent study by Teixeira et al. (2016) showed that there was no significant difference in the fishing activity of fishers listed in the phonebook and unlisted fishers.

Second, the results also showed that diary surveys could be a cost-effective option when the recruitment of participants complied with randomness and representativeness requirements. One of the keys for the implementation of a successful diary survey program is the use of a random selection system for the recruitment of participants rather than spontaneous self-volunteering. Potential options regarding this issue include the use of a RDD telephone survey (Rocklin et al. 2014) or a stratified set of recreational fishers in a licence holder registry (Wise and Fletcher 2013).

Survey designs significantly influence the cost-effectiveness of a study and the diffusion of new technology may offer great opportunities to improve the costeffectiveness of survey methods. For example, survey designs using an online 
panel may be very efficient to collect data at low cost as compared to traditional survey methods (van der Hammen et al. 2016). New data collection methods also include smartphone applications that could potentially be a source of frequent and extensive data (Venturelli et al. 2016).

\subsection{Limits}

There are a number of volunteer programs that were unsuccessful in obtaining representative samples (Bray and Schramm 2001; Smallwood et al. 2010). Also, self-selection of participants can induce large biases and the data collected can be very misleading when used to provide estimates of catch and effort (Wise and Fletcher 2013). It is worth noting that many studies and expert groups recommended that a state-wide monitoring program should also include complementary on-site surveys to provide enabled validation of information collected in the diary surveys (ICES 2010; Hartill et al. 2012; Jones and Pollock 2013; Wise and Fletcher 2013). It is clear that obtaining a representative sample and cross-validated data for the monitoring of marine recreational fishing in a multi-issue (biological, sociological, economic) and multi-species context induces considerable costs. In practice the choice of the survey method usually depends on the context of a study (Milazzo et al. 2002; Hartill et al. 2012; Jones and Pollock 2013). Also, the analysis presented in this paper focused on the quality of catch and effort data whereas it may also be profitable that monitoring schemes include the collection of economic and sociological data for management purposes (Cisneros-Montemayor and Sumaila 2010). 


\subsection{Perspectives}

The ideal survey frame would be a complete registry of recreational fishers (Ashford et al. 2009; ICES 2010, 2013; Hartill et al. 2012). Indeed, it would help build a representative sample of recreational fishers at a very low cost. An estimation of the savings in the telephone surveys costs which could be expected if such registry were implemented is proposed in Supplementary Appendix 1. Empirical evidence related potential savings also includes the fact that the costs of the surveys based on a fishing licenses registry in the Spanish Basque country (Zarauz et al. 2015) were much lower than the costs of the French surveys. This shows how much the monitoring of marine recreational activities can benefit in terms of savings in public money from implementing a complete registry of users besides expected improvements in the precision of estimations or potential use as a sampling frame for diary surveys.

With the increasing awareness of the population regarding the potential of marine recreational activities to substantially impact biodiversity, local and national decision makers need scientific expertise on this subject in order to adopt public policies. Most of the challenges faced in the monitoring of recreational fishing are largely shared by the other marine recreational activities:

- low resources to study the interactions between uses and biodiversity

- no census of users

- heterogeneity of uses

- diversity of locations 
- nomadism of users

- seasonality.

The number of users who are concerned that they participate in a self-sustainable or environment-friendly activity is also growing (Bruyere and Rappe 2007) and a greater number of citizens are inclined to get involved into monitoring schemes (Ryan et al. 2001; Conrad and Hilchey 2011; Hyder et al. 2015). The French experience of the monitoring of recreational fishing between 2004 and 2012 showed that the involvement of citizens through diary surveys could be a costeffective option. The authors of this paper believe similar methodologies, including online diary approaches too, should be considered for future implementations of marine recreational activities monitoring systems.

\section{Acknowledgements}

The authors are very grateful to Mickael Drogou and Ronan Le Goff for their helpful comments during the research and on an early version of the draft, and to Yvon Morizur and Gérard Véron for supplying information on former recreational fisheries studies conducted by Ifremer. The authors would also like to thank all the people who participated in the surveys for providing valuable data that allowed improving our knowledge of the recreational fisheries sector. This material is based upon work supported by the European Union through its community programme for the collection, management and use of data in the fisheries sector. 


\section{References}

Addessi L (1994) Human disturbance and long-term chances on a rocky intertidal community. Ecological Applications. 4, 786-797

Arlinghaus R (2006) Overcoming human obstacles to conservation of recreational fishery resources, with emphasis on central Europe. Environmental Conservation, 33(1), 46-59

Arlinghaus R, Cooke SJ (2009) Recreational fisheries: socioeconomic importance, conservation issues and management challenges. Recreational hunting, conservation and rural livelihoods: science and practice, 39-58

Ashford JR, Jones CM, Fegley L (2009) A License Registry Improves Sampling Efficiency for a Marine Recreational Survey. Transactions of the american fisheries society. 138(5), 984-989

Badalamenti F, Ramos AA, Voultsiadou E, Sanchez Lizaso JL, D'Anna G, Pipitone C, Mas J, Ruiz Fernandez JA, et al. (2000) Cultural and socio-economic impacts of Mediterranean marine protected areas. Environmental conservation, 27(02), 110-125

Bellanger M, Le Goff R, Levrel H, Drogou M (2013). Le suivi de la pêche récréative en mer : analyse coûts/efficacité des différents types d'enquête et perspectives d'évolution. Journées RBE, Brest, 5 novembre 2013, 24pp

Bray GS, Schramm HL (2001) Evaluation of a statewide volunteer angler diary program for use as a fishery assessment tool. North American Journal of Fisheries Management, 21(3), 606-615

Bruyere B, Rappe S (2007) Identifying the motivations of environmental volunteers. Journal of Environmental Planning and Management, 50(4), 503-516

Cifuentes M, Izurieta A, De Faría H (2000) Measuring protected area management effectiveness. Turrialba (Costa Rica): World Wildlife Fund.

Cisneros-Montemayor AM, Sumaila UR (2010) A global estimate of benefits from ecosystem-based marine recreation: potential impacts and implications for management. Journal of Bioeconomics, 12(3), 245-268

Conrad CC, Hilchey KG (2011) A review of citizen science and community-based environmental monitoring: issues and opportunities. Environmental monitoring and assessment, 176(1-4), 273-291 
Courrau J (1999) Monitoring protected area management in Central America: a regional approach. Parks, 9(2), 56-60.

Dalton T, Thompson R, Jin D (2010) Mapping human dimensions in marine spatial planning and management: An example from Narragansett Bay, Rhode Island. Marine Policy, 34(2), 309-319

Davenport J, Davenport JL (2006) The impact of tourism and personal leisure transport on coastal environments: a review. Estuarine, Coastal and Shelf Science, 67(1), 280292

EC (2001) Commission Regulation (EC) No. 1639/2001 of 25 July 2001 establishing the minimum and extended community programmes for the collection of data in the fisheries sector and laying down detailed rules for the application of Council Regulation (EC) No. 1543/2000. Official Journal of the European Communities, L222/44: 1-19

EC (2010) Commission decision (2010/93/EU) of 18 December 2009 adopting a multiannual community programme for the collection, management and use of data in the fisheries sector for the period 2011-2013 (EC) No 199/2008. Official Journal of the European Union, L60/51. 52 pp

Ervin J (2003) Rapid assessment of protected area management effectiveness in four countries. BioScience, 53(9), 833-841.

Fisher MR (1996) Estimating the effect of nonresponse bias on angler surveys. Transactions of the American Fisheries Society, 125(1), 118-126

Gaudin C, De Young C (2007) Recreational fisheries in the Mediterranean countries: a review of existing legal frameworks (Vol. 81). FAO

Goodman LA (1960) On the exact variance of products. Journal of the American Statistical Association, 55(292), 708-713

Gormsen E (1997) The impact of tourism on coastal areas. GeoJournal, 42(1), 39-54

Green RE, Balmford A, Crane PR, Mace GM, Reynolds JD, Turner RK (2005) A framework for improved monitoring of biodiversity: responses to the World Summit on Sustainable Development. Conservation Biology, 19(1), 56-65

Hartill BW, Cryer M, Lyle JM, Rees EB, Ryan KL, Steffe AS, Taylor SM, West L, Wise BS (2012) Scale-and context-dependent selection of recreational harvest estimation methods: the Australasian experience. North American Journal of Fisheries Management, 32(1), 109-123 
Herfaut J, Levrel H, Thébaud O, Véron G (2013) The nationwide assessment of marine recreational fishing: A French example. Ocean \& Coastal Management, 78, 121-131

Hyder K, Townhill B, Anderson LG, Delany J, Pinnegar JK (2015) Can citizen science contribute to the evidence-base that underpins marine policy? Marine Policy, 59, $112-120$.

International Council for the Exploration of the Sea (2010) Report of the planning group on recreational fisheries (PGRFS)

International Council for the Exploration of the Sea (2013) Report of the working group on recreational fisheries surveys (WGRFS)

Jones CM, Pollock KH (2013) Recreational Angler Survey Methods: Estimation of Effort, Harvest, and Released Catch. Chapter 19 in Fisheries Techniques Manual, Third Edition. American Fisheries Society

Kerbiriou C, Leviol I, Jiguet F, Julliard R (2008) The impact of human frequentation on coastal vegetation in a biosphere reserve. Journal of Environmental Management, 88(4), 715-728

Kerbiriou C, Le Viol I, Robert A, Porcher E, Gourmelon F, Julliard R (2009) Tourism in protected areas can threaten wild populations: from individual response to population viability of the chough Pyrrhocorax pyrrhocorax. Journal of Applied Ecology, 46(3), 657-665

Milazzo M, Chemello R, Badalamenti F, Camarda R, Riggio S (2002) The impact of human recreational activities in marine protected areas: what lessons should be learnt in the Mediterranean sea?. Marine ecology, 23(s1), 280-290

National Research Council (2006) Review of Recreational Fisheries Survey Methods. National Academies Press, Washington, D.C.

Pollock KH, Jones CM, Brown TL (1994) Angler survey methods and their applications in fisheries management. American Fisheries Society

Rocklin D, Levrel H, Drogou M, Herfaut J, Veron G (2014) Combining Telephone Surveys and Fishing Catches Self-Report: The French Sea Bass Recreational Fishery Assessment. PloS one, 9(1), e87271

Ryan RL, Kaplan R, Grese RE (2001) Predicting volunteer commitment in environmental stewardship programmes. Journal of Environmental Planning and Management, 44(5), 629-648 
Smallwood CB, Thomson A, Harris D, Johnston D (2010) The volunteer fisheries liaison officer program: an analysis of recreational fishing data from 1995-2007. Fisheries Research Report, (203), 46

Smallwood CB, Beckley LE, Moore SA, Kobryn HT (2011) Assessing patterns of recreational use in large marine parks: A case study from Ningaloo Marine Park, Australia. Ocean \& Coastal Management, 54(4), 330-340

Smallwood CB, Pollock KH, Wise BS, Hall NG, Gaughan DJ (2012) Expanding AerialRoving Surveys to Include Counts of Shore-Based Recreational Fishers from Remotely Operated Cameras: Benefits, Limitations, and Cost Effectiveness. North American Journal of Fisheries Management, 32(6), 1265-1276

Spearman C (1904). The proof and measurement of association between two things. The American journal of psychology, 15(1), 72-101.

Teixeira D, Zischke MT, Webley JA. (2016) Investigating bias in recreational fishing surveys: Fishers listed in public telephone directories fish similarly to their unlisted counterparts. Fisheries Research, 181, 127-136.

van der Hammen T, de Graaf M, Lyle JM (2016) Estimating catches of marine and freshwater recreational fisheries in the Netherlands using an online panel survey. ICES Journal of Marine Science: Journal du Conseil, 73(2), 441-450.

Venturelli PA, Hyder K, Skov C. (2016) Angler apps as a source of recreational fisheries data: opportunities, challenges and proposed standards. Fish and Fisheries.

Wise BS, Fletcher WJ (2013) Determination and Development of Cost Effective Techniques to Monitor Recreational Catch and Effort in Western Australian Demersal Finfish Fisheries (Fisheries Research Report no. 245). Fisheries Research Division.

Zarauz L, Ruiz J, Urtizberea A, Andonegi E, Mugerza E, Artetxe, I (2015) Comparing different survey methods to estimate European sea bass recreational catches in the Basque Country. ICES Journal of Marine Science: Journal du Conseil, 72(4), 1181-1191. 


\section{SUPPLEMENTARY APPENDIX 1: expected benefits from the implementation of a complete registry}

An estimation of the savings in the telephone surveys costs which could be expected if a complete registry of recreational fishers were implemented (this hypothesis is referred to as $\mathrm{HO}$ in the rest of this section) is now proposed. Indeed, in a standard RDD telephone survey, most of the interview time is spent interrogating non fishers. In fact, based on the results exposed in the Section 3.1, the average time spent per telephone interview was:

$$
(14677 * 3+758 * 15) / 15435=3.6 \text { mins. }
$$

But considering all the non-responses including refusals, absent, occupied, no tonality, communication problem and false number, the average time needed to search for a new respondent between two interviews was 16 minutes $^{1}$.

Only 4.9\% (=758 / 15435) of the interviews were long ones (dedicated to recreational fishers) which was approximately 1 of 20 . This means that, in average, it took:

$$
(3.6+16) * 20=392 \text { mins }=6.5 \text { hours }
$$

of work to get one 15 mins interview of a recreational fisher plus 19 short interviews. This illustrates the time consuming nature of screening surveys.

\footnotetext{
${ }^{1}$ This average searching time between two interviews has been estimated by the polling institute BVA that performed the telephone surveys in 2006, 2009 and 2011.
} 
Under HO, a screening telephone survey would still be needed to make sure the diarists are representative of the recreational fishers' population in terms of fishing activity and avidity. However, the interview time would be entirely devoted to interviewing recreational fishers. If the average searching time between 2 interviews is assumed to remain unchanged, one can expect an interview of a recreational fisher every 31 mins (= 15 min interview +16 min searching time). Balancing this with the case where there was no registry, the yield of recreational fishers interviews would be $13(=392$ / 31) times better.

The costs of interviews could be extracted out of the total costs of the telephone survey and they were found to represent more than $76 \%$ :

$97567 €($ Total costs $)=75042 €($ interviews costs $)+22525 €($ other costs $)$

Other costs $(O C)$ include the preparation of the study, data recording and creation of database, data validation and first univariate statistical treatments. Assuming at first that, under $\mathrm{HO}$, these other costs remain unchanged, one can expect that the total costs for an equivalent number of interviews of recreational fishers become:

$$
22525+75042 / 13=28300 €
$$

which is about $71 \%$ less than a screening survey without registry.

To reach this conclusion, the other costs $O C$ were supposed unchanged, but in fact those are likely to decrease as well since part of the work associated with the short interviews (e.g. data recording and validation) would cease. 